\title{
Diversity and biocide susceptibility of fungal assemblages dwelling in the Art Gallery of Magura Cave, Bulgaria
}

\author{
Milena M. Mitova ${ }^{1}$, Mihail Iliev${ }^{1}$, Alena Nováková ${ }^{2}$, Anna A. Gorbushina ${ }^{3,4}$, \\ Veneta I. Groudeva ${ }^{1}$, and Pedro M. Martin-Sanchez ${ }^{3^{*}}$
}

${ }^{1}$ Sofia University "St. Kliment Ohridski”, Faculty of Biology, 1164 Sofia, Bulgaria

${ }^{2}$ Institute of Microbiology, Academy of Sciences of the Czech Republic, v.v.i, Vídeñská 1083, 14220 Prague 4, Czech Republic

${ }^{3}$ Bundesanstalt für Materialforschung und -prüfung (BAM), Department 4 Materials \& Environment, Unter den Eichen 87, 12205 Berlin, Germany

${ }^{4}$ Freie Universität Berlin, Department of Biology, Chemistry \& Pharmacy and Department of Earth Sciences, Malteserstrasse 74-100, 12249 Berlin, Germany

\begin{abstract}
Magura Cave, north-western Bulgaria, possesses valuable rock-art paintings made with bat guano and dated from the period between the Eneolithic and Bronze Ages. Since 2008, the Art Gallery is closed to the general public in order to protect the paintings from vandalism, microclimatic changes caused by visitors and artificial illumination, and the consequent growth of fungi and phototrophs. Nevertheless, some tourist visits are allowed under the supervision of cave managers. This study provides the first scientific report on cultivable fungal assemblages dwelling different substrata in the Art Gallery. A total of 78 strains, belonging to 37 OTUs (Ascomycota $81 \%$, Zygomycota 14\%, Basidiomycota 5\%), were isolated in the study. This fungal diversity was clearly dominated by Penicillium $(50 \%$ of strains) and Aspergillus (13\%). The most relevant visible fungal colonies were detected in sediments rich in bat guano, where, besides Penicillium, other guanophilic fungi such as Mucor, Mortierella, Trichosporon and Trichoderma were dominant. Conversely, scarce fungi were detected on rock surface of painted walls. Based on the biocide susceptibility assay, octylisothiazolinone (OIT) and benzalkonium chloride (BAC) were effective inhibiting the in vitro growth of dominant fungal species in Magura Cave, when applied at concentrations ranged from 100 to $1,000 \mathrm{mg} / \mathrm{L}$. These data provide a valuable knowledge about Magura fungi, and exemplify a type of preliminary test that may be conducted before planning any biocide treatment. However, considering the irreversible effects of biocides on the ecological balance in caves, and the low fungal contamination in painted walls of Magura Cave, there is no reason to use conventional biocides in this cave. Further studies, monitoring microbial communities and microclimatic parameters, should be conducted to improve the knowledge on microbial ecology in Magura Cave and possible human impacts, as well as to allow the early detection of potential microbial outbreaks.
\end{abstract}

Keywords: fungi, cultivable microorganisms, rock-art caves, bat guano, biocides

Received 14 September 2016; Revised 3 February 2017; Accepted 3 February 2017

Citation: $\quad$ Mitova M.M., Iliev M., Nováková A., Gorbushina A.A., Groudeva V.I. and Martin-Sanchez P.M., 2017. Diversity and biocide susceptibility of fungal assemblages dwelling in the Art Gallery of Magura Cave, Bulgaria. International Journal of Speleology, 46 (1), 67-80. Tampa, FL (USA) ISSN 0392-6672 https://doi.org/10.5038/1827-806X.46.1.2061

\section{INTRODUCTION}

Magura Cave, located in Bulgaria, contains more than 700 prehistoric paintings depicting a variety of anthropomorphic figures, animals and signs that resemble letters from an unknown alphabet. These multi-layered paintings were created using bat guano, similar to those from Baylovo Cave in Bulgaria (Stoytchev, 2005) and Grotta dei Cervi in Italy (Groth et al., 2001), and dated from the period between the Eneolithic and Bronze Ages (Stoytchev, 1994). In 1984, Magura Cave was placed on the Tentative
List for consideration as World Heritage Site by the United Nations Educational, Scientific and Cultural Organization (UNESCO, Tentative list 45). In 2008, sections of the cave containing the rock art (the Art Gallery) were closed to the public in order to protect the paintings from deterioration due to (i) vandalism, (ii) microclimate warming caused by visitors and artificial lighting installed in 2001, and (iii) the consequent growth of phototrophs and fungi on the walls and sediments (Arcá, 2014). In particular, the main concern was the presence of fungal colonies on paintings in the Art Gallery (Stavreva, 2012). Despite 
the closure of the Art Gallery, some guided tourist visits are allowed under the supervision of cave managers.

Human presence in caves always leads to alternations of the microclimate, the biogeochemical cycles, and the balance of organic matter. These parameters have enormous impact on native microbial populations. Some fast growing heterotrophic microorganisms may be favored by the new conditions, and cause microbial outbreaks. However, the presence and role of microorganisms in caves is a topic that is often ignored in cave management unless any microbial crisis arises (Saiz-Jimenez, 2012). Furthermore, the decision of closing a cave to the public for conservation reasons is always a controversial topic. Sometimes economic interests prevail over conservation leading to deterioration of cultural heritage (Saiz-Jimenez et al., 2011). In rock-art caves, when visits cannot be prevented, cave management should include ways to control organic matter inputs by visitors, and periodic monitoring of microclimate and microorganisms present in all cave compartments. Microbial ecological studies can provide useful information for early detection of dangerous microbial outbreaks (Saiz-Jimenez, 2012, 2013). Knowledge about the most relevant microorganisms, such as their colonization patterns, dispersion mechanisms, and potential adverse effects on human health and rock art (if present), can help cave managers to adopt conservation measures.

A variety of studies have demonstrated that the use of biocides in caves is a dangerous choice to control microbial outbreaks (Boston et al., 2006; SaizJimenez, 2013). Boston et al. (2006) discussed the effect of different cleaning chemicals traditionally used in caves, such as chlorine bleach, soaps and solvents, on microbial communities and mineral formations. Mulec and Kosi (2009) reviewed the pros and cons of physical, chemical, and biological methods to control the phototrophic biofilms associated with artificial illumination of caves, demonstrating that all evaluated control methods have relevant weaknesses. Biocides completely change the original microbial communities, altering the natural ecological balance of the cave, and subsequent recolonizations can provoke further microbial outbreaks. In addition, when biocides are applied without the appropriate previous efficacy tests against the specific cave microbiota, the ecological effects of such treatments are totally unpredictable. Although there is no clear report about biocide treatments in Magura Cave to date, some authors mentioned that a small fraction of the paintings was treated in 1983 by Aneta Slavova, from the National Institute for Cultural Monuments, with an unknown solution which prevented fungal growth on the treated surfaces (Stavreva, 2012; Arcá, 2014).

The presence of bats is a critical challenge for conservation of rock-art caves. Bat colonies significantly affect the microbial diversity in caves due to input of organic matter through deposition of guano and carcasses, and its influence on bacterial and fungal dispersion (Vanderwolf et al., 2013; Kokurewicz et al., 2016; Ogórek et al., 2016). Bat-inhabited caves can be reservoirs of human pathogenic fungi such as Histoplasma capsulatum, causative agent of histoplasmosis (Cano \& Hajjeh, 2001), which is frequently isolated from warm caves in tropical areas. In addition, the sudden and catastrophic appearance of the White Nose Syndrome (WNS), caused by Pseudogymnoascus destructans, in cave-dwelling North American bats in 2006 has stimulated interest in cave fungi in the last few years (Blebert et al., 2009; Lorch et al., 2013). A huge bat colony of more than 2,000 individuals spends the winter in Magura Cave. A total of eight bat species with priority conservation status in Europe have been identified in Magura Cave (Bulgarian Biodiversity Foundation, "See More: FOR the Bats" project).

The bacterial assemblages inhabiting the Art Gallery of Magura Cave were recently studied by Tomova et al. (2013a, b), and Ivanova et al. (2013). However, despite the relevance of fungi in cave environments and their well-known role in rock-art deterioration, no fungal studies have been conducted to date in Magura Cave. Among other reasons, the need of a fungal study in this cave is supported by the abundance of bat guano in the whole cavity, as well as the fact that fungal colonization of paintings was reported as one of the key motivations for closing the Art Gallery to the public in 2008. Considering this lack of knowledge, the goals of this study are (i) to characterize the fungal assemblages that colonize different substrata in the Art Gallery of Magura Cave by cultivation as well as culture-independent analyses, and (ii) to evaluate the susceptibility of the most abundant cultivable fungi to different biocides.

\section{MATERIALS AND METHODS}

\section{Sampling}

Magura Cave is located near Rabisha village in the Vidin district at north-western Bulgaria. The cave has an area of $28,600 \mathrm{~m}^{2}, 2.5 \mathrm{~km}$ of underground passages, and its entrance is situated $375 \mathrm{~m}$ above

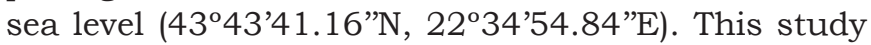
focused on the Art Gallery (Fig. 1a), placed in a left branch of the cave which can be accessed through a narrow corridor around $200 \mathrm{~m}$ from the entrance. The mean air temperature and relative humidity in this gallery is $12^{\circ} \mathrm{C}$ and $\sim 94 \%$, respectively.

Surveys were carried out 2011-2015, and samples were collected from 15 different points along the Art Gallery (Fig. 1a). A total of 35 samples were analyzed, 24 from the rock surface close or on the paintings (hereafter "painting samples", Fig. 1b-d), and 11 from cave sediments rich in bat guano (hereafter "sediment samples", Fig. 1e-g) which frequently showed growth of fungal mycelia. Painting samples were aseptically collected using cotton swabs, and sediment samples were collected in $50 \mathrm{ml}$ Falcon tubes using sterile scalpels. All samples were kept on ice during transport to the laboratory.

\section{Isolation of fungi}

Swabs of painting samples were transferred to $15 \mathrm{ml}$ Falcon tubes containing $2 \mathrm{ml}$ of sterile saline solution $(0.9 \% \mathrm{NaCl})$. Similarly, $2 \mathrm{~g}$ of sediment samples were 

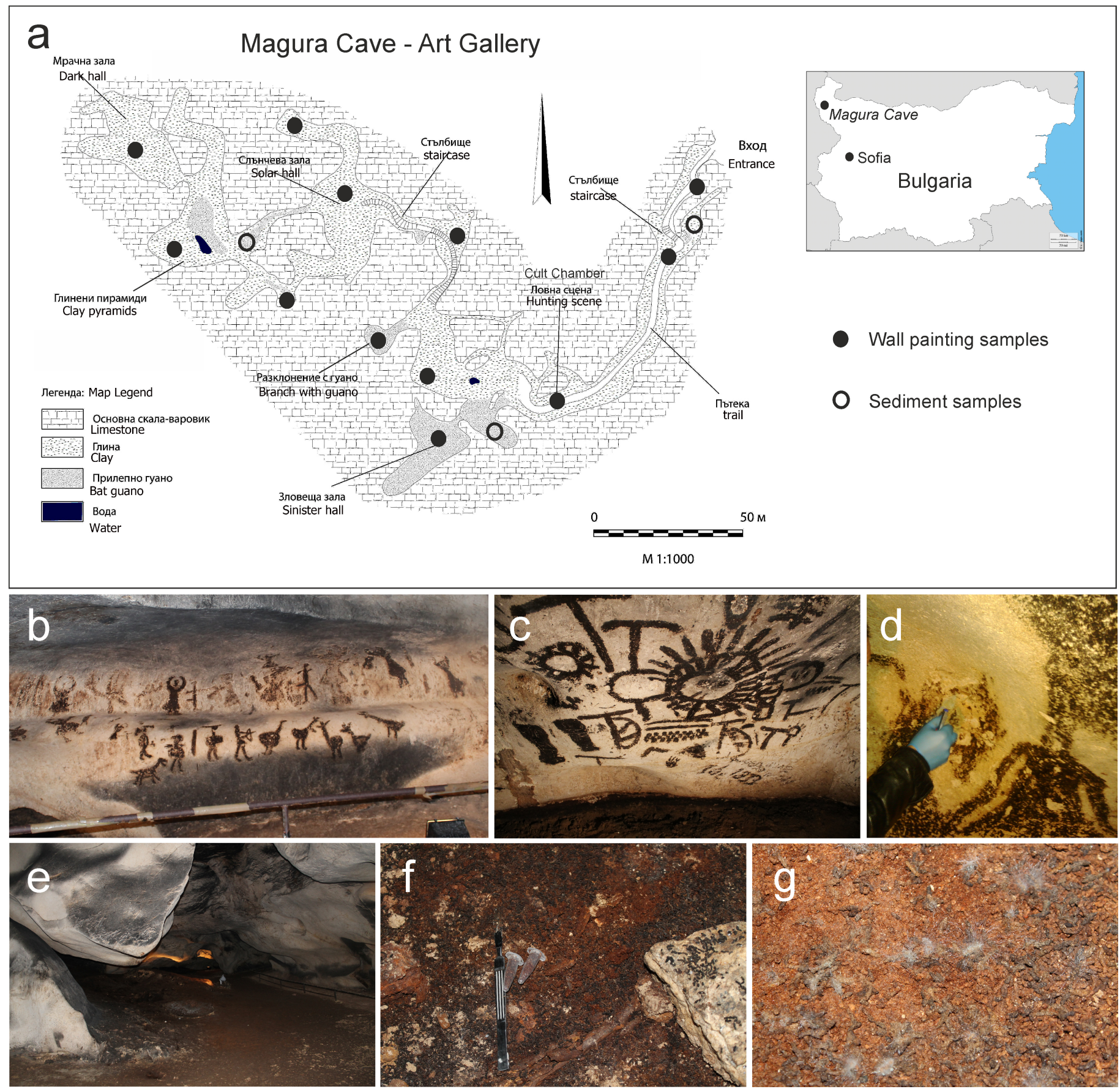

Fig. 1. a) Map of Art Gallery, Magura Cave (Vidin district, north-western Bulgaria), showing the location of sampling; b) Hunting Scene in the Cult Chamber; c) Solar Calendar in the Solar Hall; d) Sampling from wall painting; e-g) Sampling from bat guano-rich sediments, some of them showed a significant fungal colonization $(\mathrm{g})$.

transferred to $15 \mathrm{ml}$ Falcon tubes containing $10 \mathrm{ml}$ of sterile saline solution. Afterwards all samples were homogenized in the orbital shaker at $150 \mathrm{rpm}$ for 30 min. Isolation of fungi was carried out by plating in triplicate $100 \mu \mathrm{l}$ aliquots of the resulting suspensions, and three decimal serial dilutions from them, on the following culture media - potato dextrose agar (PDA), malt extract agar (MEA), Sabouraud's glucose agar (SGA) and dichloran rose bengal chloramphenicol agar (DRBC). Culture plates were incubated at $25^{\circ} \mathrm{C}$ in darkness for one month, checked every two days during the first two weeks, and once per week later. This standard incubation temperature, higher than air temperature in this cave, was chosen in order to (i) save time of analysis, because the majority of fungi grow quicker at $25^{\circ} \mathrm{C}$ than $14^{\circ} \mathrm{C}$, and (ii) compare the results to most of fungal cave studies, with similar culture conditions. Based on colony morphology, the most abundant cultivable fungi, as well as some further representative strains, were isolated in pure cultures on the same culture media. Afterwards, selected isolates were grown on MEA slants and stored at $4^{\circ} \mathrm{C}$ until subsequent analyses.

\section{Molecular identification}

Molecular identification of all fungal strains was performed by PCR and sequencing of the rDNA internal transcribed spacers (ITS) or a fragment of the 18S rRNA gene (18S). The $18 \mathrm{~S}$ marker was alternatively analyzed for some fungal strains in which the ITS analysis failed. Genomic DNA of each strain was extracted from its biomass grown on MEA. Biomass was collected and transferred to a $2 \mathrm{ml}$ Eppendorf tube containing $500 \mu \mathrm{lNE}$ buffer 
(10 mM TrisHCl, 100 mM NaCl, 1 mM EDTA; pH 8) and glass beads of three different diameters $(0.5,2$, and $5 \mathrm{~mm}$ ). The mixture was shaken at $4.5 \mathrm{~ms}-1$ for $1 \mathrm{~min}$ in a Fast Prep RiboLyser cell disrupter (Thermo Hybaid GmbH, Ulm, Germany). The DNA was purified through phenol/chloroform extraction and isopropanol precipitation. The extracted DNA was resuspended in $100 \mu$ sterile ultrapure water, and its DNA concentration was quantified using NanoDrop 2000C (Thermo Fisher Scientific, Wilmington, DE, USA), following the manufacturer's instructions.

The corresponding molecular marker was analyzed by conventional PCR for each strain, the whole ITS region using the primers ITS1 and ITS4 (White et al., 1990) or a fragment of $18 \mathrm{~S}$ using the fungal primers 0817F (Borneman \& Hartin, 2000) and 1750-3' (Gargas $\&$ Taylor, 1992). PCR reactions were performed in a BioRad C1000 Thermal Cycler (BioRad, Hercules, CA, USA). Cycling parameters for both markers were $95^{\circ} \mathrm{C}$ for $5 \mathrm{~min}$, followed by 35 cycles of $95^{\circ} \mathrm{C}$ for $30 \mathrm{~s}, 50^{\circ} \mathrm{C}$ for $30 \mathrm{~s}$, and $72^{\circ} \mathrm{C}$ for $1 \mathrm{~min}$ (ITS) or $2 \mathrm{~min}(18 \mathrm{~S})$, with a final extension at $72^{\circ} \mathrm{C}$ for $10 \mathrm{~min}$. Reactions were performed in duplicate, and negative controls (containing no DNA) were included in each PCR trial. All PCR products were checked by electrophoresis in $1.5 \%(\mathrm{w} / \mathrm{v})$ agarose gels stained with GelRed dye (Genaxxon Bioscience GmbH, Ulm, Germany) and visualized under UV light. Positive amplification products were purified by using a QIAquick PCR Purification Kit (Qiagen GmBH, Hilden, Germany) and sequenced in duplicate by Macrogen Europe Company (Amsterdam, The Netherlands) with the same primer sets used for PCR. After edition, final sequences were submitted to the European Nucleotide Archive (ENA, EMBL-EBI) under the accession numbers LT623959

LT623995. Identification of strains was based on comparison of their rDNA sequences with the GenBank database using the BLAST algorithm from the NCBI.

\section{Phylogenetic relationships}

Based on previous molecular identification, representative strains of the different fungal taxa isolated from Magura Cave were selected (Table 1). Phylogenetic relationships between such representative strains and the closest related sequences of reference strains, extracted from GenBank, were estimated. The ITS sequences were aligned using MUSCLE web service (EMBL-EBI), and the phylogenetic analyses were conducted using MEGA 5.2 with the NeighborJoining method. Gaps were treated as missing data, the Kimura 2 parameter substitution model was used, and bootstrap values were generated using 10,000 replicates. Additionally, the resulting topology was compared with results from other treeing algorithms, including the Maximum-Likelihood and MaximumParsimony methods.

\section{Morphological studies}

Morphological characteristics of representative strains (Table 1) were additionally characterized. For such purpose all fungal strains were cultivated on MEA under standard incubation conditions $\left(25^{\circ} \mathrm{C}\right.$ in darkness) for seven to ten days. If poor sporulation was achieved, longer incubation time and other nutrient media were used - e.g., PDA, carrot agar (CA) or potato carrot agar (PCA) (Atlas, 2010). In the case of Penicillium and Aspergillus strains, additional standard nutrient media were needed for the identification process - Czapek yeast autolysate agar (CYA), Blakeslee malt extract agar (BMEA), yeast extract sucrose agar (YES), and creatine sucrose agar (CREA) (Samson \& Frisvad, 2004).

The morphological identification was based on macroand micro-morphological properties (phenophytic and microscopic characters), i.e. the assessment of growth rate, colony morphology, production of exudate and soluble pigment, sporulation type, size and shape of all components of conidiophore or sporophore, type of conidiogenous cells, production of ascocarps, size and shape of ascocarps, asci, and ascospores; according to taxonomic literature and compendia (Domsch et al., 2007; de Hoog et al., 2000).

If necessary, simple physiological tests, such as Ehrlich test of color reactions and estimation of acid and base production on CREA, were also used for Penicillium and Aspergillus identification. All species were examined using a Zeiss Axio Scope.A1 microscope with Nomarski interphase contrast. Microscopic slides were prepared from cultures showing good sporulation using $60 \%$ lactic acid with fuchsin as mounting medium (Kreisel \& Schauer, 1987).

\section{Denaturing Gradient Gel Electrophoresis}

Fungal assemblages of environmental samples collected from paintings and sediments were characterized by denaturing gradient gel electrophoresis (DGGE). For comparison, the DGGE profiles of all fungal strains were also analyzed. DNA from environmental samples was extracted using the FastDNA SPIN Kit for Soil (MP Biomedicals, Solon, USA) following the manufacturer's instructions. DNA extraction protocol for fungal strains was detailed above. After PCR amplification of ITS marker, as previously described, for DGGE analysis a second round of PCR is needed, using the primers ITS1-GC (containing a GC clamp on its 5' end) and ITS2 (White et al., 1990), and $1 \mu 1$ of the first PCR product as DNA template. The cycling parameters in the second PCR were $95^{\circ} \mathrm{C}$ for $5 \mathrm{~min}$, followed by 35 cycles of $95^{\circ} \mathrm{C}$ for $1 \mathrm{~min}, 58^{\circ} \mathrm{C}$ for $1 \mathrm{~min}$, and $72^{\circ} \mathrm{C}$ for $1 \mathrm{~min}$, with a final extension at $72^{\circ} \mathrm{C}$ for $10 \mathrm{~min}$.

For DGGE fingerprint of samples, $20 \mu \mathrm{l}$ of positive PCR products (containing the ITS1 region) were analyzed. Gel electrophoresis was performed as previously described by Muyzer et al. (1993) in 0.5X TAE (20 mM Tris, $10 \mathrm{mM}$ acetate, $0.5 \mathrm{mM} \mathrm{Na} \mathrm{m}_{2}$ EDTA; $\mathrm{pH} 7.8)$, with acrylamide gels $(195 \times 160 \times 1 \mathrm{~mm})$, using 10\% (v/v) Rotiphorese Gel 30 (30\% acrylamide, 0.8\% bisacrylamide; Carl Roth GmbH, Karlsruhe, Germany) containing a gradient of denaturants (formamide and urea) of $25-45 \%$. The gels were run in a D-Code System (BioRad) for $3.5 \mathrm{~h}$ in TAE 0.5X buffer at $60^{\circ} \mathrm{C}$ and constant voltage of $200 \mathrm{~V}$. After electrophoresis, gels were stained in GelRed dye and visualized under UV light. A marker, containing the PCR products 
Table 1. Representative fungal strains isolated from Magura Cave.

\begin{tabular}{|c|c|c|c|c|c|c|c|}
\hline $\begin{array}{c}\text { Representative } \\
\text { strain }^{\mathrm{a}}\end{array}$ & $\begin{array}{l}\text { Accession } \\
\text { No. }\end{array}$ & $\begin{array}{c}\text { Number } \\
\text { of strains }\end{array}$ & Source $^{\mathrm{b}}$ & $\begin{array}{c}\text { Molecular } \\
\text { identification }^{c}\end{array}$ & $\begin{array}{l}\text { Closest related species } \\
\text { from GenBank }\end{array}$ & $\begin{array}{c}\text { Similarity } \\
(\%)\end{array}$ & $\begin{array}{l}\text { Morphological } \\
\text { identification }^{\mathrm{d}}\end{array}$ \\
\hline P5* & LT623959 & 12 & $\begin{array}{l}\text { painting / } \\
\text { sediment }\end{array}$ & Penicillium sp. & $\begin{array}{c}\text { P. cordubense, } P . \text { polonicum, } P . \\
\text { lapidosum, P. thomi }\end{array}$ & 100 & \\
\hline P7 & LT623995 & 6 & $\begin{array}{l}\text { painting / } \\
\text { sediment }\end{array}$ & Eurotiales** & Penicillium malachiteum & 100 & \\
\hline P31.1 & LT623960 & 4 & painting & Penicillium sp. & $\begin{array}{c}\text { P. commune, } P \text {. oxalicum, } P . \\
\text { camemberti }\end{array}$ & 100 & Penicillium commune \\
\hline so-3 & LT623961 & 1 & sediment & Penicillium sp. & P. lanosum, P. halotolerans & 99 & $\begin{array}{c}\text { Penicillium } \\
\text { aurantiogriseum }\end{array}$ \\
\hline $\mathrm{S} 1-4$ & LT623962 & 1 & sediment & Penicillium sp. & $P$. janthinellum, $P$. ochrochloron & 99 & $\begin{array}{l}\text { Penicillium cf. } \\
\text { janthinellum }\end{array}$ \\
\hline $2-1$ & LT623963 & 1 & painting & Penicillium sp. & P. pancosmium & 99 & \\
\hline $2-2$ & LT623964 & 1 & painting & Penicillium sp. & $\begin{array}{l}P . \text { biourgeianum, } P \text {. } \\
\text { brevicompactum }\end{array}$ & 100 & \\
\hline $2-3$ & LT623965 & 1 & painting & Penicillium sp. & $\begin{array}{c}\text { P. coprophilum, } P \text {. } \\
\text { chrysogenum, } P \text {. concentricum }\end{array}$ & 100 & $\begin{array}{l}\text { Penicillium } \\
\text { coprophilum }\end{array}$ \\
\hline $2-7$ & LT623966 & 1 & painting & Penicillium sp. & $\begin{array}{c}\text { P. echinulatum, } P . \text { commune, } P . \\
\text { solitum, } P . \text { cavernicola }\end{array}$ & 100 & Penicillium solitum \\
\hline SF20-3 & LT623967 & 1 & sediment $t^{\S}$ & Penicillium sp. & P. concentricum & 98 & \\
\hline $\mathrm{P} 23^{*}$ & LT623968 & 8 & $\begin{array}{l}\text { painting / } \\
\text { sediment }\end{array}$ & Aspergillus sp. & A. versicolor & 100 & \\
\hline $\mathrm{P} 28$ & LT623969 & 2 & $\begin{array}{l}\text { painting / } \\
\text { sediment }\end{array}$ & Aspergillus sp. & A. versicolor & 100 & \\
\hline $\mathrm{P} 3 *$ & LT623970 & 6 & $\begin{array}{l}\text { painting / } \\
\text { sediment }\end{array}$ & Simplicillium sp. & S. cylindrosporum, S. minatense & 99 & \\
\hline $5-1$ & LT623971 & 2 & painting & Chaetomiaceae & Chaetomium arxii & 98 & \\
\hline SF 15-4 & LT623972 & 2 & sediment $t^{\S}$ & Chaetomiaceae & Chaetomium piluliferum & 99 & \\
\hline $\mathrm{S} 1-8^{*}$ & LT623973 & 2 & sediment & Trichosporon sp. & T. porosum & 100 & \\
\hline SF 19-2 & LT623974 & 2 & sediment $^{\S}$ & Trichosporon sp. & T. jirovecii & 98 & \\
\hline $5-2^{*}$ & LT623975 & 3 & painting & Gymnoascus sp. & G. reessii & 99 & Gymnoascus reessii \\
\hline $\mathrm{S} 1-3$ & LT623976 & 2 & sediment & Mortierella sp. & M. parvispora, $M$. jenkinii & 99 & \\
\hline $\mathrm{S} 1-7$ & LT623977 & 1 & sediment & Mortierella sp. & M. verticillata, M. epicladia & 99 & \\
\hline $\mathrm{S} 2-6^{*}$ & LT623978 & 1 & sediment & Mucor sp. & M. circinelloides & 100 & Mucor circinelloides \\
\hline SF15-7 & LT623979 & 1 & sediment $^{\S}$ & Mucor aligarensis & M. aligarensis & 100 & \\
\hline SF20-2 & LT623980 & 1 & sediment $^{\S}$ & Mucorsp. & M. plumbeus & 100 & \\
\hline $\mathrm{P} 16$ & LT623981 & 2 & painting & Cladosporium sp. & C. variabile & 100 & \\
\hline $\mathrm{S} 1-5^{*}$ & LT623982 & 2 & sediment & Ascomycota & $\begin{array}{c}\text { Humicola grisea, Trichocladium } \\
\text { asperum }\end{array}$ & 99 & $\begin{array}{l}\text { Humicola grisea var. } \\
\text { grisea }\end{array}$ \\
\hline SO-9* & LT623983 & 1 & sediment & Trichoderma sp. & $\begin{array}{l}\text { T. koningii, } T . \text { hispanicum, } T . \\
\text { viride }\end{array}$ & 100 & \\
\hline $\mathrm{S} 1-1$ & LT623984 & 1 & sediment & Trichoderma sp. & T. harzianum & 100 & \\
\hline $\mathrm{P} 18^{*}$ & LT623985 & 1 & painting & Hypocreales & $\begin{array}{c}\text { Sarocladium zeae, Sarocladium } \\
\text { strictum }\end{array}$ & 94 & Acremonium zeae \\
\hline So-12* & LT623986 & 1 & sediment & Exophiala sp. & E. salmonis & 100 & \\
\hline $\mathrm{SO}-2^{*}$ & LT623987 & 1 & sediment & Bionectria sp. & B. rossmaniae & 99 & $\begin{array}{l}\text { B. rossmaniae or } B . \\
\text { sesquicillii }\end{array}$ \\
\hline $\mathrm{S} 1-6^{*}$ & LT623988 & 1 & sediment & Arthrinium sp. & A. arundinis & 100 & Arthrinium arundinis \\
\hline $\mathrm{S} 1-9 *$ & LT623989 & 1 & sediment & Torulaspora sp. & T. delbrueckii & 99 & \\
\hline $\mathrm{S} 2-2^{*}$ & LT623990 & 1 & sediment & Pochonia sp. & P. rubescens, $P$. suchlasporia & 98 & \\
\hline $\mathrm{S} 2-4^{*}$ & LT623991 & 1 & sediment & Doratomyces sp. & $\begin{array}{c}\text { D. stemonitis, } D \text {. } \\
\text { purpureofuscus, D. castaneus }\end{array}$ & 99 & $\begin{array}{c}\text { Doratomyces } \\
\text { microsporus }\end{array}$ \\
\hline SF3-4 & LT623992 & 1 & sediment $t^{\S}$ & Debaryomycetaceae & Debaryomyces sp. & 100 & \\
\hline S2-7 & LT623993 & 1 & sediment & Bionectriaceae & Gliomastix murorum & 100 & Gliomastrix murorum \\
\hline P31.2* & LT623994 & 1 & sediment & $\begin{array}{l}\text { Pseudogymnoascus } \\
\text { sp. }\end{array}$ & P. pannorum & 99 & \\
\hline
\end{tabular}

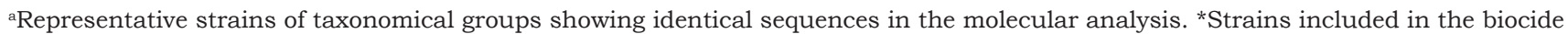
susceptibility assay (Table 2).

bIsolation source in Magura Cave, samples from the rock surface close or on the paintings collected using cotton swabs (painting), or samples from cave sediments rich in bat guano (sediment). sSediment samples showing mycelial growth visible to the naked eye.

${ }^{c}$ Molecular identification based on comparison of their ribosomal ITS sequences, except some strains (**) for which the $18 \mathrm{~S}$ rDNA gene was used because the ITS primers failed, with GenBank by BLAST algorithm from NCBI. The closest relative species are detailed.

${ }^{\mathrm{d}}$ Some strains could not be morphologically identified because they produced sterile colonies or additional studies in detail are need. 
(primers ITS1-GC/ITS2) from three abundant fungi isolated from Magura Cave (Penicillium sp. strain P4, Aspergillus sp. strain P9 and Cladosporium macrocarpum strain P16), was included to allow comparative analysis of DGGE patterns from different gels, and as a quality control for the gel run.

\section{Biocide susceptibility of fungal strains}

Biocide susceptibility of major fungi isolated from Magura Cave was tested by using the agar disc-diffusion test. Two biocidal substances were evaluated, benzalkonium chloride (BAC) and 2-octyl-3-isothiazolinone (OIT), which have a broad antimicrobial activity including against fungi. BAC, composed by mixtures of n-alkyldimethylbenzyl ammonium chlorides, belongs to the group of surfaceactive quaternary ammonium compounds and is active against bacteria, fungi, some viruses and protozoa. BAC biocidal action is due to disruption of intermolecular interactions causing dissociation of cellular membrane lipid bilayers, which compromises cellular permeability controls and induces leakage of cellular contents (Gilbert \& Moore, 2005). OIT is an isothiazolinone derivative with broad-spectrum biocidal action used to control the growth of bacteria, fungi and algae in cooling water systems, storage tanks, emulsions and paints (Kramer et al., 2008). Both compounds are widely used for conservation of many materials including culture heritage assets.

In order to evaluate accurate concentrations of biocides, high-purity active ingredients were used for both biocides, BAC at $\geq 95.0 \%$ (Sigma-Aldrich Chemie $\mathrm{GmbH}$, Munich, Germany; product number 12060) and OIT at $97.8 \%$ (non-commercial product kindly provided by Thor GmbH, Speyer, Germany). According to similar previous studies, three different biocide concentrations $(100,500$ and $1,000 \mathrm{mg} / \mathrm{L})$ were evaluated. For each strain the test was conducted on MEA plates in triplicate plus a control plate without biocide. All plates were initially inoculated with $100 \mu 1$ of the fungal suspension (described below). Afterwards three sterile Whatman paper discs ( $5 \mathrm{~mm}$ in diameter) were placed on the medium and subsequently soaked with $15 \mu$ of the corresponding biocide concentration. Plates were incubated at $25^{\circ} \mathrm{C}$ in darkness for 10 days and measurements of the inhibition zones around the discs were recorded.

For fungal inoculation, cell suspensions were prepared in sterile phosphate-buffered saline solution (PBS; $137 \mathrm{mM} \mathrm{NaCl}, 2.7 \mathrm{mM} \mathrm{KCl}, 10 \mathrm{mM} \mathrm{Na}_{2} \mathrm{HPO}_{4}$, $1.8 \mathrm{mM} \mathrm{KH} \mathrm{KO}_{4} ; \mathrm{pH}$ 7.4), from 2 week-old MEA cultures of selected strains, following two different procedures depending on sporulation rate. For fungi with high sporulation, conidia were collected washing the colony surface with $5 \mathrm{ml}$ PBS using a sterile pipet. For slow growing fungi or those with poor sporulation, mycelia were mixed with $10 \mathrm{ml} \mathrm{PBS}$ and $5 \mathrm{~mm}$ metal beads, and subsequently homogenized in a Retsch MM400 mill (Retsch GmbH, Haan, Germany) for 10 min at $30 \mathrm{~Hz}$. The cell concentration of all resulting suspensions was very high, developing a homogeneous growth over the whole surface of culture plate in a few days (2-7) after inoculation with $100 \mu \mathrm{l}$.

\section{RESULTS AND DISCUSSION}

\section{Fungal assemblages inhabiting Magura Art Gallery}

A total of 78 strains, belonging to 37 operational taxonomic units (OTUs; whose members show identical sequences), were isolated during the study (Table 1). According to the phylogenetic study (Fig. 2 and 3), the majority of OTUs belong to the phylum Ascomycota (30 OTUs, 81\%), in contrast to fewer Basidiomycota (two Trichosporon species) and Zygomycota (five species of the genera Mucor and Mortierella). Among the ascomycetes, fourteen OTUs were from class Eurotiomycetes, with the major genera Penicillium (10 OTUs, 39 strains) and Aspergillus (2 OTUs, 10 strains), and twelve OTUs were included in class Sordariomycetes, with a more diverse representation of taxa.

All OTU-representative strains were further morphologically characterized to be identified at the species level. However, only twelve strains (32\%) have been identified using this approach (Table 1) due to the well-known limitations of such studies. For some studied strains, such as Aspergillus sp. P23, additional morphological, physiological and/ or phylogenetic studies would be needed for reliable identification. Other strains, such as Mortierella sp. S1-3, only produced sterile colonies which prevented their characterization. The phylogenetic trees (Fig. 2 and 3) show the final consensus identification of strains using both molecular and morphological data.

Regarding DGGE characterization of Magura strains, in general the OTUs detailed in Table 1 showed distinctive patterns, like those Penicillium strains belonging to the most abundant OTU (Fig. 4a). As demonstrated in previous studies (Martin-Sanchez et al., 2012), the fungal strains in pure culture frequently develop characteristic multiband DGGE profiles, due to PCR artifacts, which complicates the interpretation of DGGE results from diverse environmental samples. In this sense, Neilson et al. (2013) concluded that DGGE provides an excellent tool for comparative community structure analysis, but such method-specific artifacts preclude its use for accurate quantitative diversity analysis.

In general, the fungal diversity found in the Art Gallery was rather low with clear dominance of a few genera. However, as well known in literature, cultivable populations do not represent the true diversity of the ecosystem. Less than $1 \%$ of the estimated microbial diversity is thought to be cultivable in laboratory conditions due to the very low growth rate of many environmental microorganisms (Amann et al., 1995). In addition, the selected culture methods, media and incubation conditions, have most likely favored these genera against the rest of microbes. In accordance with many previous cultivation-based studies in other caves (Vanderwolf et al., 2013), the fungal community in Magura Cave was clearly dominated by Penicillium and Aspergillus species (Fig. 3). Most of Penicillium strains (59\%) were taxonomically placed in the subgenus Penicillium, section Fasciculata, according to the classification of Houbraken and Samson (2011) and Visagie et al. (2014a), including the species 


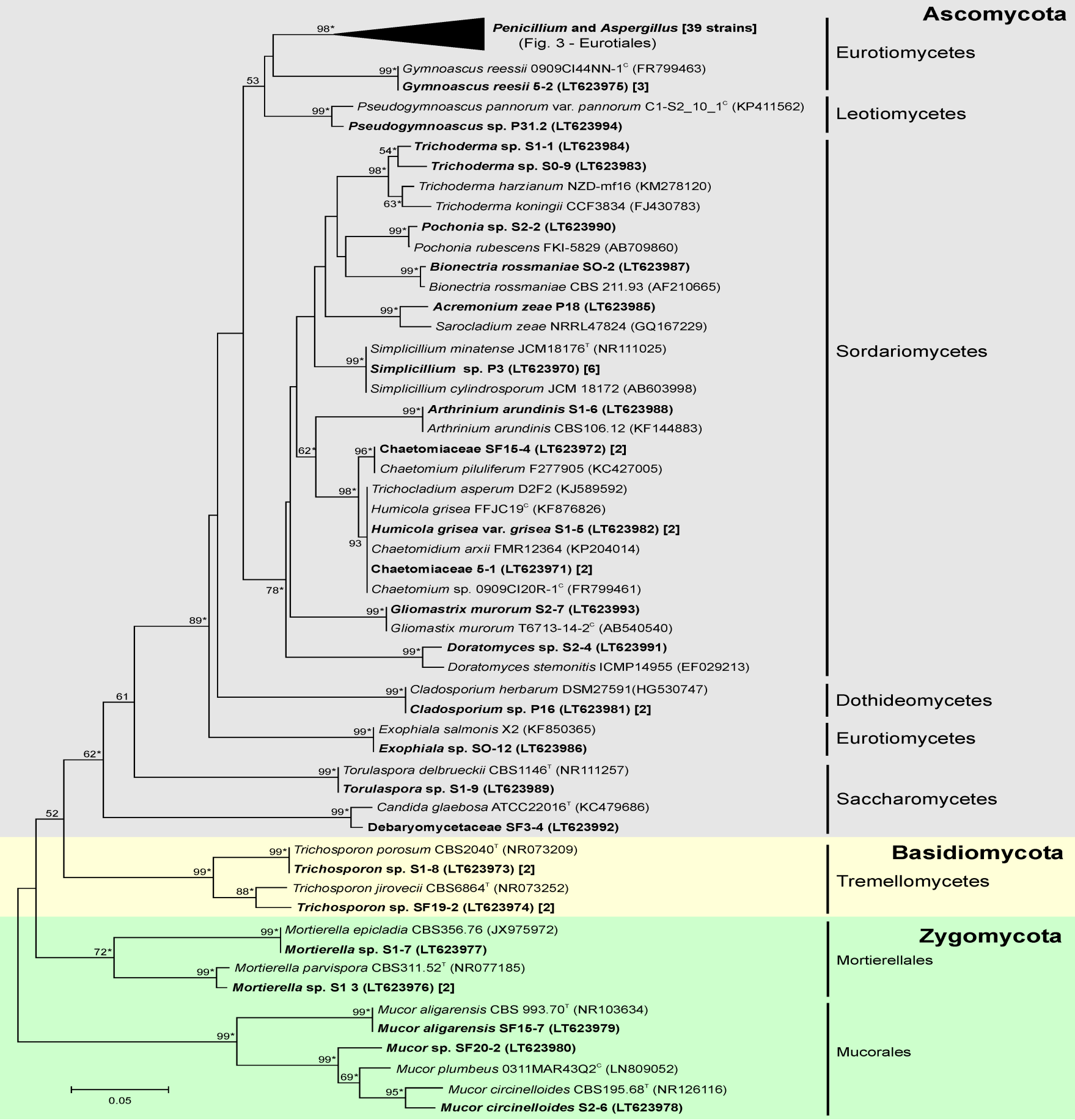

Fig. 2. Fungal phylogeny of the ITS region showing the taxonomical placement of representative strains from Magura Cave (in bold) and the closest reference strains, including type strains $\left(^{\top}\right)$ and isolates from caves $\left(^{(}\right)$. The major taxon Eurotiales was compressed and detailed in Fig. 3. Numbers of strains higher than one are presented in brackets. The unrooted tree was constructed using the Neighbor-Joining method applying the Kimura 2 parameter model. All positions containing gaps and missing data were eliminated. There were a total of 235 positions in the final dataset. The tree was bootstrapped 10,000 times and values above $50 \%$ are indicated at nodes. The asterisks indicate branches of the tree that were also recovered using Maximum-Likelihood and Maximum-Parsimony treeing algorithms. Bar, 0.05 substitutions per nucleotide position.

P. commune and P. solitum. Six Eurotiales strains, with $\mathrm{P} 7$ as representative, were closely related to Penicillium malachiteum (subgenus Aspergilloides, section Sclerotiora) based on the analysis of their $18 \mathrm{~S}$ rRNA gene sequences (Table 1). However, they could not be included in the phylogenetic analysis focused on ITS region. Members of Chaetomiaceae family and genera such as Simplicillium, Trichosporon, Gymnoascus, Mortierella, Mucor, Cladosporium and Trichoderma were repeatedly isolated in the studied samples. Most of genera isolated from Magura Cave were frequently found in previous studies of air samples from indoor environments, and either in sediment or rock surface samples from other caves in Europe (Vanderwolf et al., 2013). This is logical considering the high concentration of airborne fungal spores expected in caves like Magura, populated by bat colonies and accessible to tourists, with the consequent inputs of organic matter.

Ascomycota appears to be the most abundant phylum in any natural environment irrespective of whether culture dependent or independent approaches are used. According to previous studies (Nováková et al., 2009; Docampo et al., 2011; Vanderwolf et al., 2013; Man et al., 2015), the most abundant fungal genera in caves are Penicillium, Aspergillus, Cladosporium, 


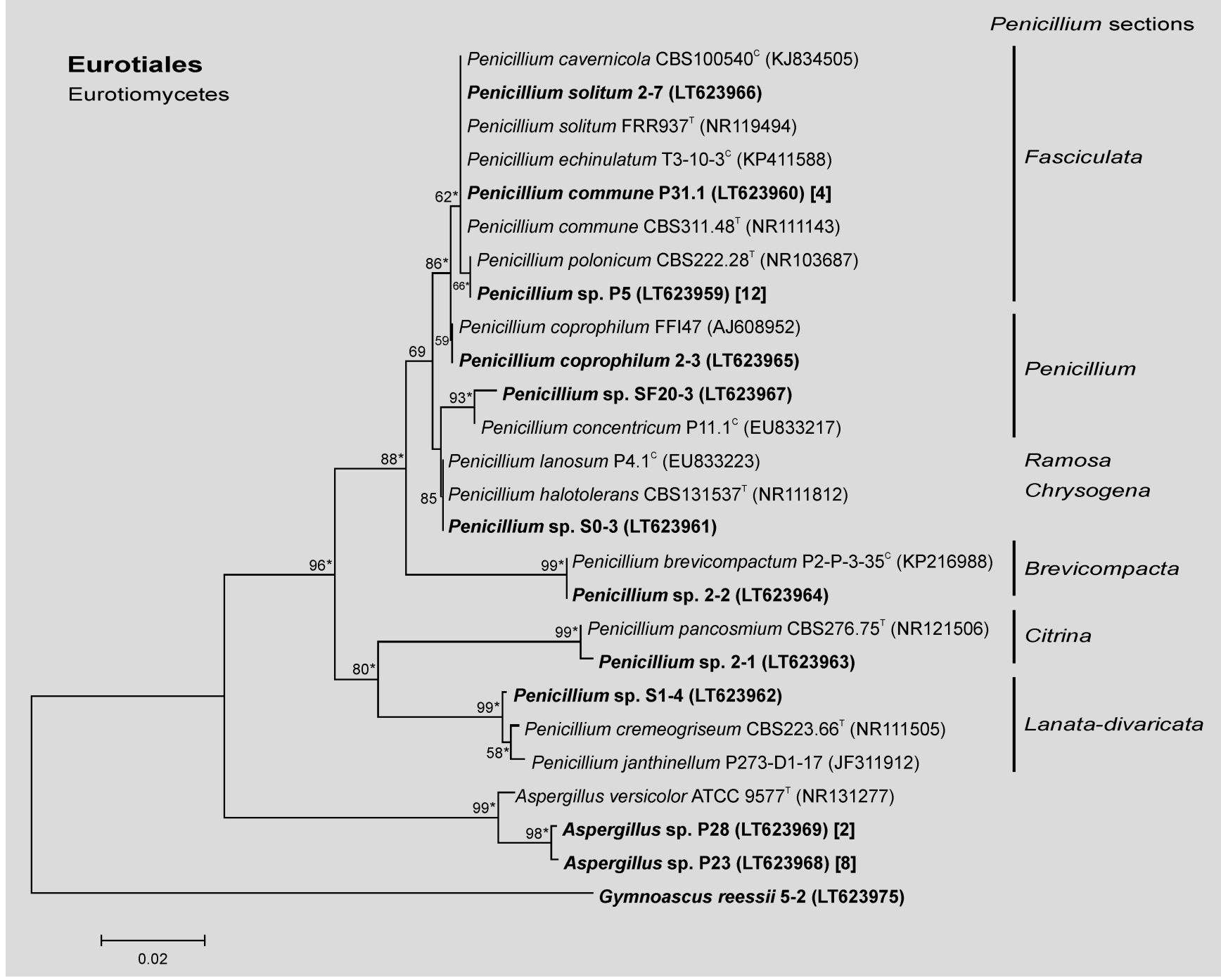

Fig. 3. Eurotiales phylogeny of the ITS region showing the placement of representative Penicillium and Aspergillus strains from Magura Cave (in bold) and the closest reference strains, including type strains $\left({ }^{\top}\right)$ and isolates from caves $\left.{ }^{(}\right)$. Penicillium sections according to Houbraken and Samson (2011) are shown. Numbers of strains higher than one are presented in brackets. The tree was constructed using the NeighborJoining method applying the Kimura 2 parameter model, and rooted with Gymnoascus reessii 5-2 as outgroup. All positions containing gaps and missing data were eliminated. There were a total of 445 positions in the final dataset. The tree was bootstrapped 10,000 times and values above $50 \%$ are indicated at nodes. The asterisks indicate branches of the tree that were also recovered using Maximum-Likelihood and Maximum-Parsimony treeing algorithms. Bar, 0.02 substitutions per nucleotide position.

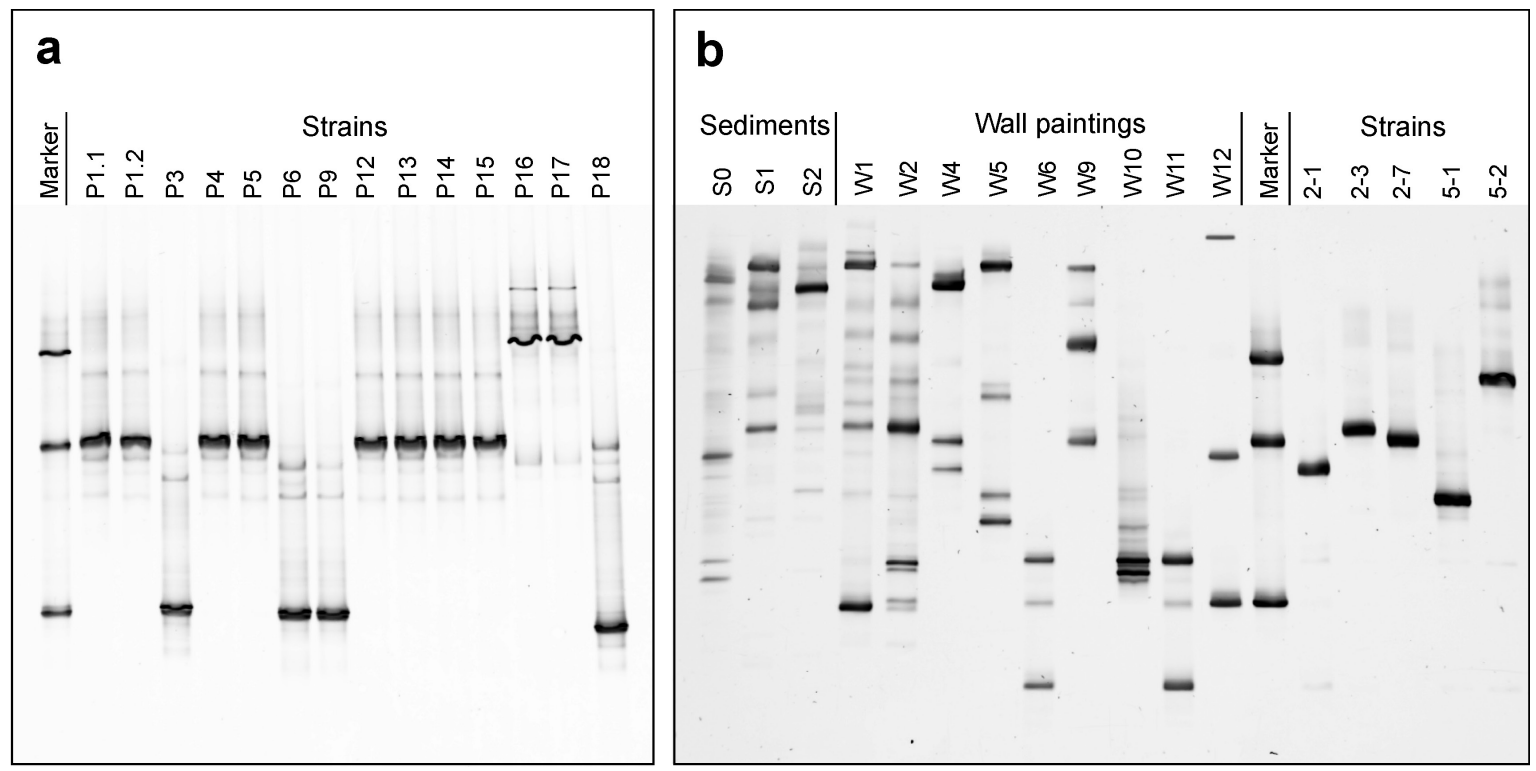

Fig. 4. DGGE profiles of fungal strains and environmental samples from Magura Cave. a) Strains Penicillium sp. P5 (= P1.1, P1.2, P4, P12, P13, P14, P15), Simplicillium sp. P3 (= P6), Aspergillus sp. P9, Cladosporium sp. P16 (= P17) and Acremonium zeae P18; marker composed by the strains P4, P9 and P16; b) Sediment samples (S) rich in bat guano, wall painting samples (W) collected from rock surface close or on the paintings, and some strains from samples W2 (Penicillium sp. 2-1, Penicillium coprophilum 2-3 and Penicillium solitum 2-7) and W5 (Chaetomiaceae 5-1 and Gymnoascus reessii 5-2). 
Mucor, Fusarium and Trichoderma, which may be due to their ubiquitous distribution in nature. Aspergillus/ Penicillium was the most abundant spore type found in the air of Nerja Cave, Spain, which represented 50\% of the total spores, followed by Cladosporium with $17 \%$ (Docampo et al., 2011). Penicillium and Aspergillus species grow better in warm and humid environments but can tolerate wide ranges of temperature and $\mathrm{pH}$. They are ubiquitous molds that grow on organic matter producing abundant conidia which enhance their fast spreading (Visagie et al., 2014b).

\section{Rock surface of painted walls}

As described by Man et al. (2015) in Heshang Cave, China, differences in abundance and composition of fungal assemblages were detected comparing different substrata of Magura Cave. First, it is noteworthy to mention than we did not detect relevant in situ fungal growth on the rock surface of painted walls in the different sampling campaigns. Evident fungal mycelia were only observed in a few small areas near the paintings, which were especially targeted for sampling. This fact could explain the low number of colonies grown on culture media from the painting samples collected using swabs. For instance, cultivable fungi were only isolated from three (W2, W5, and W11) of twelve painting samples collected in the last sampling campaign in 2015. However, the DGGE patterns corresponding to nine of these samples showed more diverse assemblages (Fig. 4b), remarking the prevalence of non-cultivable fungi on this substratum. Despite the commented limitations of DGGE (Neilson et al., 2013), which hinder the comparison between environmental samples and isolated strains, results show that structure of fungal assemblages on rock surfaces is rather different depending on studied location. Samples W1 and W2, collected from nearby areas in the entrance of Art Gallery, showed similar patterns between them, and different to samples collected from other locations in the gallery. Moreover, the main members of these assemblages most likely correspond to non-cultivable fungi under the selected media and incubation conditions. Penicillium, Aspergillus, Simplicillium, Gymnoascus and Cladosporium were the most representative genera cultivated from these samples. The genera Aspergillus and Penicillium belong to the group of fermentative microorganisms which excrete a variety of organic acids that can cause biodeterioration of rock substratum (Sterflinger, 2000).

\section{Bat guano-rich sediments}

On the other hand, in sediment samples rich in bat guano, high abundance of colonies and diversity were found by culturing, and subsequently confirmed by DGGE (Fig. 4b). Although Penicillium remains the major group in this substratum, other genera such as Trichosporon, Mortierella, Mucor, Humicola and Trichoderma were also abundant there, while none of them were detected on rock surfaces. In particular, for those sediment samples showing mycelial growth visible to the naked eye (Fig. 1g), members of genera Mucor, Penicillium and Trichosporon, and families
Chaetomiaceae and Debaryomycetaceae, were identified (Table 1). Most likely, based on morphology, such fungal growth was mainly caused by Mucor species. Jurado et al. (2010) reported similar mycelial growth on sediments of Castañar de Ibor Cave, Spain, during a fungal outbreak associated with the species Mucor circinelloides and Fusarium solani.

Nováková (2009) reported a comprehensive fungal inventory (195 taxa) from Domica Cave system, Slovakia. The highest number of taxa (92) was found in bat guano samples, where species of genera Penicillium, Mucor, Doratomyces and Trichoderma were prevalent. Furthermore, Mucor species often formed visible colonies on bat droppings and surface of guano heaps from these caves. Bat guano samples from other Slovakian caves were recently studied by Ogórek et al. (2016), with Penicillium, Aspergillus, Mucor and Rhizopus as dominant genera. Trichosporon species are widespread in cave sediments, especially in those rich in bat guano, which highlights the relevance of this cave substratum as reservoir of potentially pathogenic fungi (Saiz-Jimenez, 2012). This basidiomycetous yeast-like genus has frequently been reported as causal agent of superficial infections, as well as opportunistic agent of invasive infections (Colombo et al., 2011). Different studies have reported novel Trichosporon species isolated from sediments of bat-inhabited caves in Japan and Slovakia (Sugita et al., 2005; Nováková et al., 2015). Likewise, many Mortierella species were usually isolated from bat dung samples collected in caves in Japan (Degawa \& Gams, 2004). Species of the genera Mucor, Mortierella, Trichoderma and Pseudogymnoascus were cultured from dead bats in Berryton Cave, Canada, being the fast growing Zygomycetes, Mucor and Mortierella, particularly abundant on freshly dead bats (Vanderwolf et al., 2016). The results confirm that members of genera found in Magura Cave are significant constituents in many karstic caves. Their ecological function and possible impact on the paintings are not well understood yet.

The main input of organic matter in Magura Cave is clearly from the bat colony inhabiting this cavity long time ago, with the consequent accumulation of bat guano in sediments of the whole Art Gallery, and recurrent presence of visible fungal colonies covering these sediments. However, according to our observations and results, the fungal growth on rock surface of painted walls has been quite scarce up to date. As expected and demonstrated in this study, the current fungal community in Magura Cave is mainly composed by guanophilic species. Considering that Magura paintings were made using bat guano, this cave has most likely been inhabited by bats and their associated guanophilic microbiota since the origin of paintings thousands of years ago. Therefore, any conservation measure addressed to reduce organic matter inputs by controlling bat populations, and/or cleaning bat guano, does not make sense. Besides, such proposals would not be conceivable with current bat protection rules. The potential input of organic matter coming from tourists may be considered insignificant in comparison to bat guano contribution. 
However, humans can critically affect environmental conditions in caves, e.g. increasing variables such as temperature and carbon dioxide concentration, and lead to an ecological imbalance that stimulates the growth of certain microorganisms causing microbial outbreaks.

\section{Fungal susceptibility to biocides}

The susceptibility of Magura fungi to two of the most commonly used biocides, BAC and OIT, was additionally evaluated by agar disc-diffusion test. A total of seventeen strains, representative of the major phylotypes dwelling in the Art Gallery, were studied (Table 2). In general, both biocides were able to inhibit the fungal growth on culture plates when applied at described concentrations (100, 500 and 1,000 $\mathrm{mg} / \mathrm{L})$. These concentrations are significantly lower than those specified in manufactures' instructions of commonly used commercial products, in general ranged from 1 to $25 \mathrm{~g} / \mathrm{L}$. Only Trichoderma sp. strain S0-9 was resistant to all tested BAC doses. The majority of studied strains showed much higher susceptibility to OIT in comparison to BAC (Fig. 5a-c), except for yeast species. Torulaspora sp. S1-9 showed the opposite trend (Fig. 5d-f) and Trichosporum sp. S1-8 showed similar susceptibility to both biocides. The lowest OIT concentration tested (100 mg/L) inhibited all fungi, except Trichoderma sp., causing a significant inhibition zone diameter $(>16 \mathrm{~mm})$ in 13 of 17 strains. In this sense, it is noteworthy to mention the high inhibition degree of some fungi, such as Penicillium sp., Exophiala sp., Doratomyces sp. and Pseudogymnoascus sp., to 500 and 1,000 mg/L OIT, which could not accurately be assessed because of their great inhibition zones (diameters $>50 \mathrm{~mm} ;++++$ ). The most susceptible fungi to BAC were the mentioned yeasts, Trichosporum sp. and Torulaspora sp, as well as Exophiala sp., with inhibition zone diameters lower than $30 \mathrm{~mm}$ (Table 2). Growth inhibition by BAC was very limited (5-15 mm diameter) or nonexistent in 9 of 17 evaluated species, including the prevalent Simplicillium sp., Mucor circineilloides, and Trichoderma sp.

These results provide valuable knowledge about the susceptibility of cave fungi to common biocides. According to these data, in general, one may think that a biocide treatment based on both active substances (especially OIT), could be a useful tool to control the fungal growth in Magura Cave. However, biocide efficacy is questionable in cave ecosystems because of the presence of complex biofilms, inaccessible to biocides, and the fast inactivation of biocides through biotic and abiotic factors (Martin-Sanchez et al. 2012). In this sense, about the in vitro biocide assay included in this study, it should be noted that inhibition zones shown in Table 2 were recorded after a few days of incubation (ranged from 2 to 7 days, mostly 3 days), during the initial phase of fungal growth. However, afterwards, fungal colonies began to colonize the inhibition zone progressively reducing its area with the time. Hence, it is expected that efficacy of biocides will be limited to a time period after application, especially under natural cave environmental conditions.

Some cave restoration efforts in the last decades applied conventional biocides leading to detrimental effects on the complex microbial communities inhibiting caves (Saiz-Jimenez, 2013). Intense biocide treatments were applied in Lascaux Cave

Table 2. Biocide susceptibility of fungi isolated from Magura Cave.

\begin{tabular}{|c|c|c|c|c|c|c|c|}
\hline \multirow[t]{2}{*}{ Strains $^{a, b}$} & \multirow[t]{2}{*}{ Identification } & \multicolumn{3}{|c|}{$\begin{array}{c}\text { Benzalkonium chloride } \\
\text { Growth inhibition }\end{array}$} & \multicolumn{3}{|c|}{$\begin{array}{l}\text { 2-Octyl-3-isothiazolinone } \\
\text { Growth inhibition }\end{array}$} \\
\hline & & $100 \mathrm{mg} / \mathrm{L}$ & $500 \mathrm{mg} / \mathrm{L}$ & $1,000 \mathrm{mg} / \mathrm{L}$ & $100 \mathrm{mg} / \mathrm{L}$ & $500 \mathrm{mg} / \mathrm{L}$ & $1,000 \mathrm{mg} / \mathrm{L}$ \\
\hline $\mathrm{P} 14^{*}$ & Penicillium sp. & + & + & ++ & +++ & +++ & ++++ \\
\hline $2-7$ & Penicillium solitum & - & + & ++ & +++ & +++ & +++ \\
\hline P38* & Aspergillus sp. & + & + & ++ & ++ & +++ & +++ \\
\hline P3 & Simplicillium sp. & - & + & + & ++ & +++ & +++ \\
\hline $\mathrm{S} 1-8$ & Trichosporon sp. & + & ++ & ++ & + & ++ & ++ \\
\hline $5-2$ & Gymnoascus reessii & + & + & ++ & ++ & +++ & +++ \\
\hline $\mathrm{S} 2-6$ & Mucor circinelloides & - & - & + & + & + & ++ \\
\hline $\mathrm{S} 1-5$ & Humicola grisea var. grisea & + & + & + & ++ & ++ & ++ \\
\hline S0-9 & Trichoderma sp. & - & - & - & - & ++ & ++ \\
\hline $\mathrm{P} 18$ & Acremonium zeae & - & + & + & +++ & +++ & +++ \\
\hline so-12 & Exophiala sp. & + & ++ & ++ & +++ & ++++ & ++++ \\
\hline s0-2 & Bionetria rossmaniae & - & + & + & +++ & +++ & +++ \\
\hline S1-6 & Arthrinium arundinis & - & + & + & +++ & +++ & +++ \\
\hline S1-9 & Torulaspora sp. & + & ++ & ++ & + & + & + \\
\hline $\mathrm{S} 2-2$ & Pochonia sp. & - & + & + & +++ & +++ & +++ \\
\hline $\mathrm{S} 2-4$ & Doratomyces sp. & - & + & ++ & +++ & ++++ & ++++ \\
\hline P31.2 & Pseudogymnoascus sp. & - & + & + & ++++ & ++++ & ++++ \\
\hline
\end{tabular}

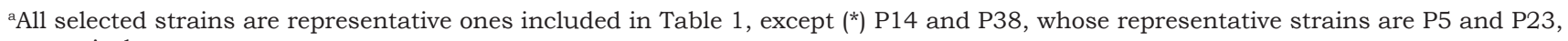
respectively.

${ }^{\mathrm{b}}$ Inhibition zones were measured after 3 days of incubation $\left(25^{\circ} \mathrm{C}\right.$, darkness), except for the strains $\mathrm{S} 2-6$ (after 1 day), $5-2$ and $\mathrm{S} 2-2$ (after 2 days), P3 (after 4 days), and S0-12 (after 1 week).

'Scale according to inhibition zone diameter: no inhibition (-), 5 - $15 \mathrm{~mm} \mathrm{(+),} 16-30 \mathrm{~mm}(++), 31-50 \mathrm{~mm}(+++)$, and >50 $\mathrm{mm}(++++)$. Values of inhibition zone diameter were average of three replicates. 

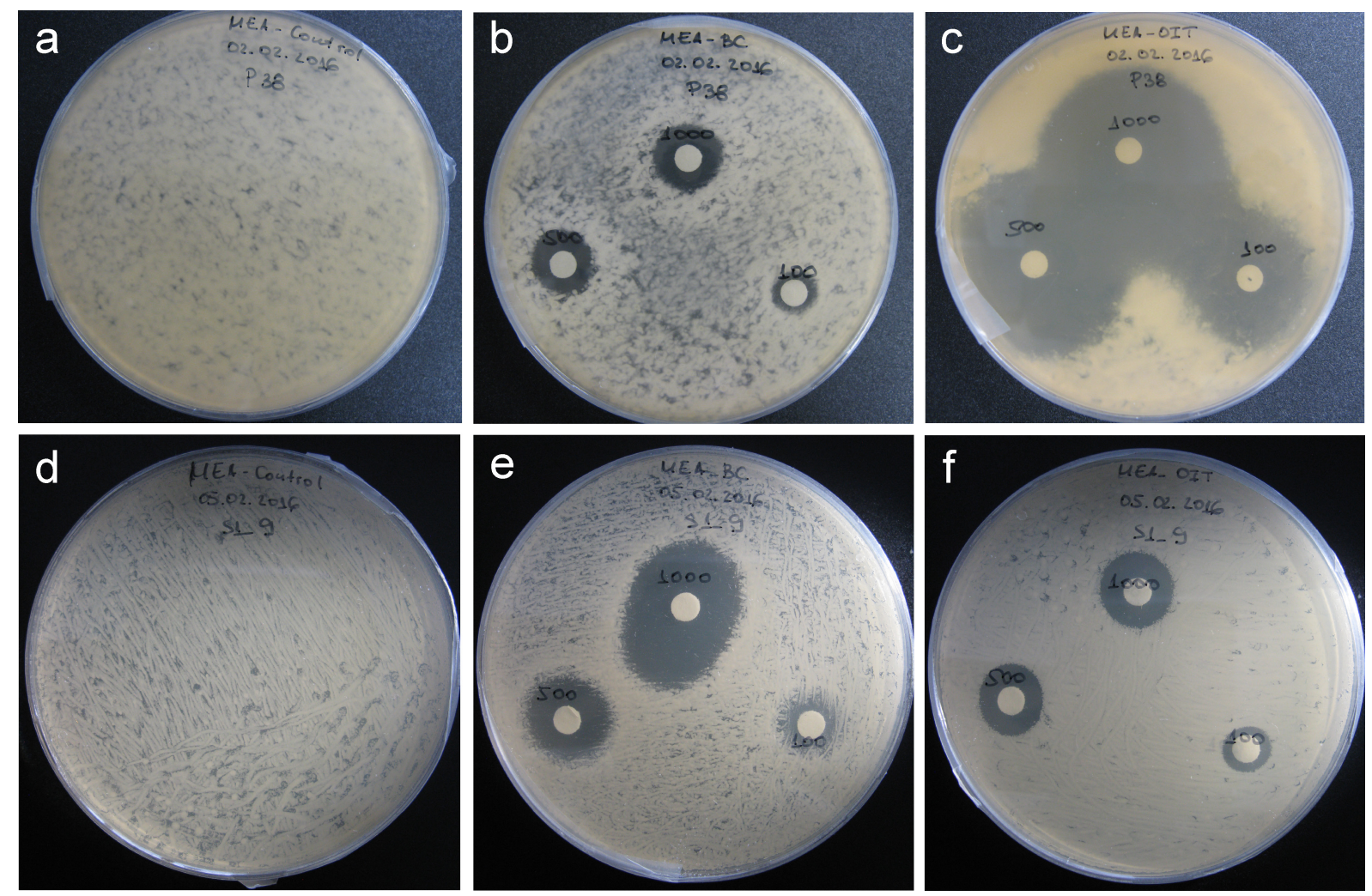

Fig. 5. Inhibition of fungal growth by the biocides benzalkonium chloride (BAC) and 2-octyl-3-isothiazolinone (OIT) in the agar disc-diffusion test. a-c) Cultures of Aspergillus sp. P38 on MEA after 3 days, control without biocide (a) and effect of different concentrations of BAC (b) and OIT (c); d-f) Cultures of Torulaspora sp. S1-9 on MEA after 3 days, control (d), BAC (e) and OIT (f). Biocide concentration in the discs: $100 \mathrm{mg} / \mathrm{L}$ (bottom right), $500 \mathrm{mg} / \mathrm{L}$ (bottom left) and 1,000 mg/L (top).

during several periods over years, mainly based on BAC but including other compounds such as OIT, formaldehyde, streptomycin sulphate and polymyxin sulphate. In particular, BAC concentrations used were ranged from 5 to $25 \mathrm{~g} / \mathrm{L}$, and OIT concentrations around $1 \mathrm{~g} / \mathrm{L}$ (Martin-Sanchez et al., 2015). Such prolonged chemical treatments caused negative effects to the cave environment, and selected resistant microorganisms which later played a key role in the black stain outbreak (Bastian et al., 2009; MartinSanchez et al., 2012, 2015). Akatova et al. (2009) evaluated the efficiency of different cleaning protocols on phototrophic biofilms of Salpetre Cave (Collbató, Spain), including mechanical removal using $70 \%$ ethanol and subsequent treatment with BAC biocides. The treated areas of speleothems were monitored under white or green light. After one year, none of the treatments was fully effective to control the recolonization by phototrophic microorganisms in the stalactite illuminated with white light. Recently, Urzi et al. (2016) reported the changes of the microbial assemblages in green/greyish phototrophic biofilms from Domitilla Catacombs (Rome, Italy) caused by a biocide treatment with the same compounds, BAC (8-12 g/L) and OIT (1.4-2 g/L). In this study, such biocides had little effect on cyanobacteria, but caused significant changes on bacterial population increasing its number and diversity.

Some authors have proposed the use of hydrogen peroxide as an environmental friendly alternative to control microbial outbreaks (Faimon et al., 2003; Boston et al., 2006). Jurado et al. (2010) reported satisfactory results using this product to control the fungal outbreak in Castañar de Ibor Cave, Spain, mainly associated with Mucor species. They proposed carrying out mechanical removal of visible fungal colonies followed of disinfestation of affected areas by hydrogen peroxide application. The main advantage of hydrogen peroxide is its degradation in contact with organic matter towards harmless molecules for the cave environment such as water and free oxygen gas.

\section{CONCLUSIONS}

Rock-art caves, like Magura Cave, are one of the most valuable properties of our ancient cultural heritage which attract massive tourism. For an appropriate cave management, especially in rock-art caves opened for visitors, it is essential to investigate the diversity and ecological role of microorganisms inhibiting there. This study provides the first scientific report on cultivable fungal assemblages dwelling different substrata in the Art Gallery of Magura Cave. As typical for caves, the fungal diversity in this gallery was clearly dominated by Penicillium and Aspergillus species which might due to their ubiquitous distribution in the nature. The most obvious growth of fungal mycelia in this gallery was observed in sediments rich in bat guano. These samples showed much higher number and diversity of colonies grown on culture plates than samples collected from rock surface of painted walls. Besides Penicillium, the dominant phylotypes in these sediments were guanophilic fungi such as Mucor, Mortierella, Trichosporon and Trichoderma. Conversely, on the rock, a few small areas near the paintings showed evident fungal mycelia, and scarce fungi were isolated from some of these samples. 
Based on biocide susceptibility assay, the active compounds BAC and OIT were effective inhibiting the in vitro growth of dominant species from Magura Cave when applied at concentrations ranged from 100 to $1,000 \mathrm{mg} / \mathrm{L}$. These data provide a valuable knowledge about Magura fungi, and exemplify a kind of preliminary test that may be conducted before planning any biocide treatment. However, considering the irreversible effects of biocides on the ecological balance in cave environments, multiple factors should carefully be evaluated before taking such critical decision in caves with rock-art paintings. As described by Martin-Sanchez et al. (2012), preliminary studies on possible advantages and disadvantages of applying biocides in each particular case are required. Any biocide treatment should be planned after testing the active compounds under different conditions, including (i) laboratory assays like in this study, but also (ii) field assays in real conditions, which are very difficult to design properly. In Magura Cave, considering the low fungal contamination in rock surfaces of painted walls, and the previously mentioned risks, there is no reason to use conventional biocides. These treatments should be avoided in order to preserve the relatively stable current balance, which of course is already altered compared to its original natural condition. Alternatively, if a more significant fungal outbreak arises, cleaning protocols combining careful mechanical removal of fungal biomass and subsequent disinfection of affected areas using hydrogen peroxide could be conducted, as long as this cleaning treatment does not lead to damages in rock-art paintings.

Human visitors can influence the quantity and diversity of microbiota in caves through of microclimate changes, organic inputs as well as lighting systems. Such human impacts only could partially be predicted by periodic microclimatic and microbiological studies. To the best of our knowledge, in Magura Cave, there was no microclimatic study up to date, and the microbiological reports are still scarce to shed light on its microbial ecology. Hence, further studies, monitoring of microbial communities and microclimatic parameters in the different cave substrata, should be conducted in order to improve the knowledge on microbial ecology in Magura Cave and to allow the early detection of potential microbial outbreaks.

\section{ACKNOWLEDGEMENTS}

The study was supported by the National Science Fund of Ministry of Education and Science, Bulgaria (Project №ДДВУ/02-73/2010), Project 13/2013/ SU, and the Bundesanstalt für Materialforschung und -prüfung (BAM), Berlin, Germany. MM thanks to the Erasmus+ Programme of the European Commission which funded her scholarship at the BAM. PMMS thanks to the Adolf Martens Fellowship Programme of the BAM. The authors are especially grateful to Dr. Jörg Toepel for scientific advices and support during laboratory works, and to Dr. Ute Schoknecht for providing the biocides used in this study. Comments and corrections of three anonymous reviewers were extremely valuable to improve this article.

\section{REFERENCES}

Akatova E., Roldan M., Hernandez-Marine M., Gonzalez J.M. \& Saiz-Jimenez C., 2009 - On the efficiency of biocides and cleaning treatments in restoration works of subterranean monuments. In: Science and cultural heritage in the Mediterranean area. Regione Siciliana, Palermo, p 316-322.

Amann R.I., Ludwig W. \& Schleifer K.H., 1995 Phylogenetic identification and in-situ detection of individual microbial cells without cultivation. Microbiological Reviews, 59: 143-169.

Arcá A., 2014 - Magura Cave paintings, Bulgarian rock art. TRACCE Online Rock Art Bulletin, 33, Nov 2014, http: / / www.rupestre.net/tracce/?p $=8048$

Atlas R.M., 2010 - Handbook of Microbiological Media, vol. $1,4^{\text {th }}$ ed. CRC Press, Boca Raton. https://doi.org/10.1201/EBK1439804063

Bastian F., Alabouvette C., Jurado V. \& Saiz-Jimenez C., 2009 - Impact of biocide treatments on the bacterial communities of the Lascaux Cave. Naturwissenschaften, 96: 863-868.

https://doi.org/10.1007/s00114-009-0540-y

Blehert D.S., Hicks A.C., Behr M., Meteyer C.U., Berlowski-Zier B.M., Buckles E.L., Coleman J.T., Darling S.R., Gargas A., Niver R., Okoniewski J.C., Rudd R.J. \& Stone W.B., 2009 - Bat white-nose syndrome: an emerging fungal pathogen? Science, 323: 227. https://doi.org/10.1126/science.1163874

Borneman J. \& Hartin R.J., 2000 - PCR primers that amplify fungal rRNA genes from environmental samples. Applied and Environmental Microbiology, 66: 4356-4360. https://doi.org/10.1128/AEM.66.10.4356-4360.2000

Boston P.J., Northup D.E. \& Lavoie K.H., 2006 - Protecting microbial habitats: Preserving the unseen. In: HildrethWerker V. \& Werker J. (Eds.), Cave conservation and restoration. National Speleological Society, Huntsville, AL, p 61-82.

Bulgarian Biodiversity Foundation - See More: FOR the Bats project. http://zaprilepite.biodiversity.bg/en/ Bulgarian Biodiversity Foundation [accessed: August 17, 2016]

Cano M.V. \& Hajjeh R.A., 2001 - The epidemiology of histoplasmosis: a review. Seminar Respiratory Infection, 16: 109-118.

https://doi.org/10.1053/srin.2001.24241

Colombo A.L., Padovan A.C.B. \& Chaves G.M., 2011 - Current knowledge of Trichosporon spp. and Trichosporonosis. Clinical Microbiology Reviews, 24: 682-700. https://doi.org/10.1128/CMR.00003-11

de Hoog G.S., Guarro J., Gené J. \& Figueras M.J., 2000 - Atlas of Clinical Fungi. 2nd ed. CBS and Universitat Rovira i Virgili, Utrecht and Reus, 1126 p.

Degawa Y. \& Gams W., 2004 - A new species of Mortierella, and an associated sporangiiferous mycoparasite in a new genus, Nothadelphia. Studies in Mycology, 50: 567-572.

Docampo S., Trigo M.M., Recio M., Melgar M., GarciaSanchez J. \& Cabezudo B., 2011 - Fungal spore content of the atmosphere of the Cave of Nerja (southern Spain): diversity and origin. Science of the Total Environment, 409: 835-843.

https://doi.org/10.1016/j.scitotenv.2010.10.048

Domsch K.H., Gams W. \& Anderson T.-H., 2007 Compendium of Soil Fungi. $2^{\text {nd }}$ ed., IHW Verlag, Eching bei München, $672 \mathrm{p}$. 
Faimon J., Stelcl J., Kubesová S \& Zimák J., 2003 - Environmentally acceptable effect of hydrogen peroxide on cave "lamp-flora", calcite speleothems and limestones. Environmental Pollution, 122:417-422. https://doi.org/10.1016/S0269-7491(02)00309-3

Gargas A. \& Taylor J.W., 1992 - Polymerase chainreaction $(P C R)$ primers for amplifying and sequencing nuclear 18S rDNA from lichenized fungi. Mycologia, 84: 589-592. https://doi.org/10.2307/3760327

Gilbert P. \& Moore L.E., 2005 - Cationic antiseptics: diversity of action under a common epithet. Journal of Applied Microbiology, 99: 703-715.

https://doi.org/10.1111/j.1365-2672.2005.02664.x

Groth I., Schumann P., Laiz L., Sanchez-Moral S., Cañaveras J.C. \& Saiz-Jimenez C., 2001 Geomicrobiological study of the Grotta dei Cervi, Porto Badisco, Italy. Geomicrobiology Journal, 18: 241-258. https://doi.org/10.1080/01490450152467778

Houbraken J. \& Samson R.A., 2011 - Phylogeny of Penicillium and the segregation of Trichocomaceae into three families. Studies in Mycology, 70: 1-51. https://doi.org/10.3114/sim.2011.70.01

Ivanova V., Tomova I., Kamburova A., Tomova A., Vasileva-Tonkova E. \& Kambourova M., 2013 High phylogenetic diversity of bacteria in the area of prehistoric paintings in Magura cave, Bulgaria. Journal of Cave and Karst Studies, 75: 218-228. https://doi.org/10.4311/2012MB0279

Jurado V., Porca E., Cuezva S., Fernandez-Cortes A., Sanchez-Moral S., Saiz-Jimenez C., 2010 Fungal outbreak in a show cave. Science of the Total Environment, 408: 36323638.

https://doi.org/10.1016/j.scitotenv.2010.04.057

Kokurewicz T., Ogórek R., Pusz W. \&·Matkowski K., 2016 - Bats increase the number of cultivable airborne fungi in the "Nietoperek" bat reserve in western Poland. Microbial Ecology, 72: 36-48.

https://doi.org/10.1007/s00248-016-0763-3

Kramer A., Reichwagen S., Widulle H. \& Heldt P., 2008 - Isothiazoline. In: Assadian O. \& Kramer A. (Eds.), Wallh"außers praxis der Sterilisation, Desinfektion, Antiseptik und Konservierung, 1st ed. Georg Thieme Verlag, Stuttgart, p. 819-820.

Kreisel H. \& Schauer F., 1987 - Methoden des mykologischen Laboratoriums. VEB Gustav Fischer Verlag, Stutgart, 173 p.

Lorch J.M., Muller L.K., Russell R.F., O’Connor M., Lindner D.L. \& Blehert D.S., 2013. - Distribution and environmental persistence of the causative agent of white-nose syndrome, Geomyces destructans, in bat hibernacula of the eastern United states. Applied and Environmental Microbiology, 79: 1293-1301. https://doi.org/10.1128/AEM.02939-12

Man B., Wang H., Xiang X., Wang R., Yun Y. \& Gong L., 2015 - Phylogenetic diversity of culturable fungi in the Heshang Cave, central China. Frontiers in Microbiology, 21: 1158. https://doi.org/10.3389/fmicb.2015.01158 Martin-Sanchez P.M., Nováková A., Bastian F.,

Alabouvette C. \& Saiz-Jimenez C. 2012 - The use of biocides for the control of fungal outbreaks in subterranean environments: the case of the Lascaux Cave in France. Environmental Science and Technology, 46: 37623770.

https://doi.org/10.1021/es2040625

Martin-Sanchez P.M., Miller A.Z. \& Saiz-Jimenez C., 2015 - Lascaux Cave: an example of fragile ecological balance in subterranean environments, In: Engel A.S. (Ed.), Microbial Life of Cave Systems, De Gruyter, p.279-302.

https://doi.org/10.1515/9783110339888-015
Mulec J. \& Kosi G., 2009 - Lampenflora algae and methods of growth control. Journal of Cave and Karst Studies, 71: 109-115.

Muyzer G., De Waal E.C. \& Uitterlinden A.G., 1993 Profiling of complex microbial populations by denaturing gradient gel electrophoresis analysis of polymerase chain reaction amplified genes coding of $16 S$ rRNA. Applied and Environmental Microbiology, 59: 695-700.

Neilson J.W., Jordan F.L. \& Maier R.M., 2013 Analysis of artifacts suggests DGGE should not be used for quantitative diversity analysis. Journal of Microbiological Methods, 92: 256-263.

https://doi.org/10.1016/j.mimet.2012.12.021

Nováková A., 2009 - Microscopic fungi isolated from the Domica Cave system (Slovak Karst National Park. Slovakia). A review. International Journal of Speleology, 38 (1): 71-82. https://doi.org/10.5038/1827-806X.38.1.8

Nováková A., Savická D. \& Kolařík M., 2015 - Two novel species of the genus Trichosporon isolated from a cave environment. Czech Mycology, 67: 233-239.

Ogórek R., Dyląg M., Kozak B., Višňovská Z., Tančinová D. \& Lejman A., 2016 - Fungi isolated and quantified from bat guano and air in Harmanecka and Driny Caves (Slovakia). Journal of Cave and Karst Studies, 78: 41-49. https://doi.org/10.4311/2015MB0108

Saiz-Jimenez C., Cuezva S., Jurado V., FernandezCortes A., Porca E., Benavente D., Cañaveras J.C. \& Sanchez-Moral S., 2011 - Paleolithic art in peril: policy and science collide at Altamira Cave. Science, 334: 42-43. https://doi.org/10.1126/science.1206788

Saiz-Jimenez C., 2012 - Microbiological and environmental issues in show caves. World Journal of Microbiology and Biotechnology, 28: 2453-2464. https://doi.org/10.1007/s11274-012-1070-x

Saiz-Jimenez C., 2013 - Cave conservation: A microbiologist's perspective. In: Cheeptham, N. (Ed.), Cave microbiomes: A novel resource for drug discovery. Springer Briefs in Microbiology, 1: 69-84. https://doi.org/10.1007/978-1-4614-5206-5_4

Samson R.A. \& Frisvad J., 2004 - Penicillium subgenus Penicillium: new taxonomic schemes and mycotoxins and other extrolites. Studies in Mycology, 49, p. 257.

Stavreva V., 2012 - Parasitic fungi are eating up the drawings in the Magura Cave. Severozapazena Bulgaria website, http://severozapazenabg.com/en

Sterflinger K., 2000 - Fungi as geologic agents. Geomicrobiology Journal, 17: 97-124. https://doi.org/10.1080/01490450050023791

Stoytchev T., 1994 - Eneolithic paintings from Magoura cave, Bulgaria. (in Bulgarian; English summary). Annuary of Department of Architecture NBU, 1: 307-320.

Stoytchev T., 2005 - Rock art: general classification (In Bulgarian). Agato Press, Sofia, Bulgaria, p. 24.

Sugita T., Kikuchi K., Makimura K., Urata K., Someya T., Kamei K., Niimi M. \& Uehara Y., 2005 - Trichosporon species isolated from guano samples obtained from batinhabited caves in Japan. Applied and Environmental Microbiology, 71: 7626-7629.

https://doi.org/10.1128/AEM.71.11.7626-7629.2005

Tomova I., Lazarkevich I., Tomova A., Kambourova M. \& Vasileva-Tonkova E., 2013a-Diversity and biosynthetic potential of culturable aerobic heterotrophic bacteria isolated from Magura Cave, Bulgaria. International Journal of Speleology, 42 (1): 65-76.

https://doi.org/10.5038/1827-806X.42.1.8

Tomova A., Tomova I., Vasileva-Tonkova E., Lazarkevich I., Stoilova-Disheva M., Lyutskanova D. \& Kambourova M., 2013b - Myroides guanonis sp. nov., isolated from prehistoric paintings. International Journal of Systematic and Evolutionary Microbiology, 63: 4266-4270.

https://doi.org/10.1099/ijs.0.050831-0 
UNESCO - The Magoura cave with drawings from the bronze age. http://whc.unesco.org/en/tentativelists/ 45/ UNESCO [accessed: August 17, 2016].

Urzì C., De Leo F., Krakova L., Pangallo D. \& Bruno L., 2016 - Effects of biocide treatments on the biofilm community in Domitilla's catacombs in Rome. Science of the Total Environment, 572: 252-262.

https://doi.org/10.1016/j.scitotenv.2016.07.195

Vanderwolf K.J., Malloch D., Mcalpine D.F. \& Forbes G.J., 2013 - A world review of fungi, yeasts, and slime molds in caves. International Journal of Speleology, 42 (1): 77-96. https://doi.org/10.5038/1827-806X.42.1.9

Vanderwolf K.J., Malloch D. \& McAlpine D.F., 2016 - Fungi on white-nose infected bats (Myotis spp.) in Eastern Canada show no decline in diversity associated with Pseudogymnoascus destructans (Ascomycota: Pseudeurotiaceae). International Journal of Speleology, 45 (1): 43-50.

https://doi.org/10.5038/1827-806X.45.1.1946
Visagie C.M., Houbraken J.C., Hong S.B., Klaasen C.H., Perrone G., Seifert K.A., Varga J., Yaguchi T. \& Samson R.A., 2014a - Identification and nomenclature of the genus Penicillium. Studies in Mycology, 78: 343-371. https://doi.org/10.1016/j.simyco.2014.09.001

Visagie C.M., Hirooka Y., Tanney J.B., Whitfield E., Mwange K., Meijer M., Amend A.S., Seifert K.A. \& Samson R.A., 2014b - Aspergillus, Penicillium and Talaromyces isolated from house dust samples collected around the world. Studies in Mycology, 78: 63-139.

https://doi.org/10.1016/j.simyco.2014.07.002

White T.J., Bruns T., Lee S. \& Taylor J., 1990 Amplification and direct sequencing of fungal ribosomal RNA genes for phylogenetics. In: Innis M.A., Gelfand D.H., Sninsky J.J. \& White T.J. (Eds.), PCR Protocols: A guide to methods and applications. Academic Press, London, p. 315-322.

https://doi.org/10.1016/b978-0-12-372180-8.50042-1 